\title{
Larval Terapi ve Kronik Yaralar
}

\author{
Larval Therapy and Chronic Wounds
}

\author{
Umut Gazi ${ }^{1}$, Ayşegül Taylan Özkan², Kosta Y. Mumcuoğlu ${ }^{3}$ \\ ${ }^{1}$ Tibbi Mikrobiyoloji ve Klinik Mikrobiyoloji Anabilim Dal, Tip Fakültesi, Yakın Doğu Üniversitesi, Lefkoşa, KKTC \\ ${ }^{2}$ Tibbi Mikrobiyoloji Anabilim Dal, Tip Fakültesi, Hitit Üniversitesi, Çorum, Türkiye \\ ${ }^{3}$ Parasitology Unit, The Hebrew University- Hadassah Medical School, Dept. of Microbiology and Molecular Genetics, Jerusalem, Israel
}

Yazışma Adresi / Correspondence:

Prof. Dr. Ayşegül Taylan Özkan

Tıbbi Mikrobiyoloji Anabilim Dalı,Tip Fakültesi, Hitit Üniversitesi, Çorum, Türkiye E-mail: aysegultaylanozkan@hitit.edu.tr

Orcid

Aysegul Taylan Özkan : https://orcid.org/0000-0001-8421-3625

Umut Gazi : https://orcid.org/0000-0001-9945-478X

Geliş Tarihi / Received : 06-03-2019 Kabul Tarihi / Accepted : 30-03-2019 Yayın Tarihi / Online Published: 30-09-2019

Gazi U., Özkan A.T.,Mumcuoğlu K.Y., Larval Terapi ve Kronik Yaralar,

J Biotechnol and Strategic Health Res. 2019;3(Özel Sayı):55-60 DOI: bshr.536577

\begin{abstract}
Özet
İyileşmeyen yaralar günümüzde halk sağlığı için önemli bir sorun teșkil etmeye devam etmektedir ve antibiyotiğe dirençli mikroorganizmaların sebep olduğu cilt ve yumușak doku enfeksiyon prevalansındaki artıs gibi faktörler nedeniyle bugün ilișkili oldukları vaka sayıları hâlâ artmaktadır. Yara iyileșmesi, genellikle sorunsuz ilerleyen dört örtüşen fizyolojik aşamadan oluşur: homeostaz, iltihaplanma, çoğalma ve yeniden olgunlaşma. Bununla birlikte, iyileşmeyen yaralarda, iyileşme genellikle doku döküntülerinin uzaklaştııılması, lokal enfeksiyon ve/veya proteazlar gibi yıkıcı ürünlerin yara yatağından uzaklaştırılması ile alakalı olan enflamatuar fazda durur. Larval terapi (LT) umut verici tedavi yöntemlerinden biridir ve esas olarak nekrotize edilmiș dokularla beslenen yeșil șișe sineği Lucilia sericata'nın dezenfekte edilmis larvalarının (kurtçukların) kullanılmasını içerir. LT'nin esas olarak üzerinde en fazla çalışmanın yayımlandığı debridmanın yanında dezenfeksiyon ve büyüme uyarımı ile yara iyileşmesine yardımcı olduğu düşünülmektedir. Kronik yaraların tedavisi pahalıdır ve LT uygun maliyetli bir alternatif tedavi stratejisi sunar. Öte yandan, bakteriyel kaynaklı ülserlerin tedavisine ek olarak, mikotik enfeksiyon ve leishmaniasis ile ilişkili semptomlar için de kullanılabilir. Günümüzde LT, iyileșmeyen cilt ve yumuşak doku yaralarına karșı FDA onaylı bir terapidir. Bu derlemede, iyileșmeyen yaraların tedavisinde LT tarafından kullanılan etki mekanizmaları hakkındaki güncel literatürü özetledik.

Anahtar Larval tedavi, debridman, dezenfeksiyon, büyüme uyarımı.

Non-healing wounds are still a burden to public health, and their prevalence in the population is increasing with the time due to antibiotic-resistant, microbe-associated skin and soft tissue infections as well as to the ever aging population. Wound healing is composed of four overlapping physiological phases which usually progress smoothly: homeostasis, inflammation, proliferation, and remodelling / maturing. In cases of nonhealing wounds, however, healing is usually trapped in inflammatory phase which is associated with the removal of tissue debris, local infection, and/or destructive products such as proteases from the wound bed. Maggot debridement therapy (MDT) is one of the promissing treatment modalities and it involves the use of disinfected larvae (maggots) of the green bottle fly Lucilia sericata, which feed primarily on necrotized tissue. MDT is thought to aid wound healing mainly by debridement, disinfection, and growth stimulation, among which debridement is the best studied. Management of chronic wounds is expensive, and MDT provides a cost-effective alternative treatment. In addition to to the treatment of bacterial caused ulcers, it can also be used for symptoms associated with mycotic infection, and leishmaniasis. Today, MDT is a FDA-approved therapy against non-healing skin and soft tissue wounds. In this review we summarised the current literature regarding the action mechanisms used by MDT during the treatment of non-healing wounds.

Keywords Maggot therapy, Lucilica sericata, debridement, disinfection, growth stimulation 


\section{Giriş}

Gelişmiş teknolojiye rağmen, kronik yara vakaları günümüzde halk sağlığında ciddi bir sorun olmaya devam etmektedir. Yaşam sürelerinin artması, ölümcül hastalıkların kronik hastalıklara dönüşmesi ve antibiyotiğe dirençli bakterilerin yol açtığ 1 cilt ve yumuşak doku enfeksiyon prevalansının artması gibi faktörler nedeniyle vaka sayıları günümüzde daha da artış göstermektedir. Öte yandan kronik yara vaka tedavisinin maliyetli olduğu bilinen bir gerçektir. Türkiye'de yapılan bir çalışmada, diyabetik ayak ülser tedavisinin ortalama toplam maliyetinin hasta başına 1.400 dolardan fazla olduğu bildirilmiştir ${ }^{1,2}$. Daha etkili ve ucuz bir yara bakımı sağlanması amacıyla geçmişte kullanılan tedavi stratejileri ileri teknoloji ve bakış açılarıyla yeniden yorumlanmaktadır. Bu yaklaşımlardan biri, yüzyıllardır kullanılmakta olan ve canlı sinek larvalarının yaralara uygulanmasını içeren maggot debridman tedavisi veya bir diğer adıyla larval tedavi (LT)'dir' ${ }^{3-5}$.

LT’nin yararlı etkisi ilk kez 16. yüzyılda Fransız cerrah Ambroise Pare tarafından belirtilmiş olsa da, tedavinin ilk kez resmen belgelenmesi John Forney Zacharias tarafından Amerikan İç Savaşı (1861-1865) yıllarında gerçekleşmiştir. Öte yandan LT, 19. yüzyılda Robert Koch ve Louis Pasteur öncülüğünde geliştirilen mikrop teorisi nedeniyle gözden düşmüş, ama I. Dünya Savaşı sırasında antiseptik aletlerin yeterli olmadığı durumlarda, kırıklar ve mide yara tedavisinde etkili olduğunu bildiren askeri ortopedist William Baer tarafından tekrar popülerlik kazanmıştır (46). Tedaviye ilgi yeniden 1940 'lı yıllarda antibiyotiklerin yaygın bir şekilde kullanılmaya başlanması ile düşüş göstermiş ve 1980'lerin sonunda, antimikrobiyal direnç oranlarındaki artıştan ötürü tekrar ilgi görmeye başlamıştır ${ }^{2,4,5}$. LT'de kullanılan larvalar, sağlıklı dokulardan ziyade nekrotize edilmiş hücrelerden beslenen, dezenfekte ve sterilize edilmiş yeşil şişe sineği Lucilia sericata (Phaenicia sericata olarak da bilinir) larvalarıdır. Larvaların yaradan çıkmasını engellemek ve salınan sindirim enzimlerine karşı koruma sağlamak amacı ile yaranın üst kısmı yarayı çevreleyen hidrokolloid malzemeye sabitlenmiş ağ görevi gö- ren naylon tül ile kaplanır ${ }^{7,8}$. Tedavi sırasında yara yüzeyi pansuman içinde 1-3 gün boyunca 5-10 larva/cm2'lik yoğunlukta tutulur².

\section{ETKİ MEKANİZMALARI}

Yara iyileşmesi dört fizyolojik onarım aşamasına ayrılabilir: 1- homeostaz, 2- enflamasyon, 3- çoğalma ve 4- yeniden şekillenme ve olgunlaşma. Bu dört faz genellikle düzgün bir şekilde ilerlerken, bazı durumlarda iyileşme bu fazlardan birinde, ama tipik olarak doku döküntülerinin, lokal enfeksiyonun ve/veya proteazlar gibi yıkıcı ürünlerin yara yatağından çıkarılmasında etkili olan enflamatuar fazda sıkışıp kalabilir. LT’nin temel olarak debridman, dezenfeksiyon ve büyüme uyarımı ile yara iyileşmesine yardımcı olduğu düşünülmektedir ${ }^{4,5,8}$.

\section{LT ile debridman}

İlk prospektif kontrollü çalışma, LT’nin yeniden canlanmasının kilit figürü Ronald Sherman tarafından gerçekleştirilmiştir. Çalışmada, LT’nin omurilik yaralanmalı hastalarda basınç ülserlerinin tedavisi üzerindeki etkisi araştırılmış ve yüzey alanı ve iyileşme oranları takip edilmiştir. Tedavi sonucunda, LT’nin nekrotik yaraların çoğunu herhangi bir komplikasyona neden olmadan, diğer tüm cerrahi olmayan yöntemlerden daha hızlı debride ettiği bildirilmiştir'. Sherman’ın grubu tarafından yapılan başka bir çalışmada LT’nin, her türlü geleneksel tedaviye dirençli olan kronik iki taraflı plantar ayak ülserini tedavi edebildiği rapor edilmiştir ${ }^{10^{*}}$.

Wayman ve arkadaşları tarafından 2000 yılında yapılan bir başka çalışmada LT’nin, ülseri nekrotik hücrelerden temizlemede başarılı olduğu ve tek seans larva uygulamasının tüm hastalarda etkin debridmanı sağladığı belirtilmiştir ${ }^{11}$. Markevich ve arkadaşlarının tertiplediği başka bir çalışmada, kronik diyabetik nöropatik ayak yaraları olan 140 hastaya geleneksel tedavi veya LT uygulanmış; 10 günlük takip süresinin sonunda LT’nin geleneksel tedaviye kıyasla debridmanın ve iyileşmenin sağlanmasında iki kat daha etkili olduğu gösterilmiştir ${ }^{3,12}$. Dumville ve arkadaşlarının 
çalışmasında ise, nevrotik bacak ülser vakalarında hidrojel terapisine kıyasla LT’nin daha hızlı debridman sağlamasına rağmen bakteri yük ve iyileşme oranlarında, her iki hasta grubu arasında, herhangi bir farklılık gözlenmediği ifade edilmiştir ${ }^{13}$. Diğer yandan, başka bir çalışmada, LT grubundaki iyileşme sürelerinin, kontrol grubuna kıyasla daha kısa olduğu bildirilmiştir ${ }^{14}$. Ek olarak, daha yakın tarihli bir çalışmada, LT’nin düzensiz ve nekrotik dokuların yara yatağından uzaklaştırılmasında; venöz veya karma arter/venöz bacak ülserlerininin debdridmanında kontrol olarak alınan hidrojel tedavisinden daha hızlı ve etkili olduğu gözlenmiştir ${ }^{15}$.

Öte yandan, Gilead ve arkadaşlarının yaptığı başka bir çalışmada, LT tedavisinin uygulandığ 723 ayakta ve hastanede yatan ayak ülseri hastalarının 357 (\%82.1) 'sinde tam debridman bildirilmiştir ${ }^{16}$. Bunu destekleyen başka bir çalışmada, Tantawi ve arkadaşları çalışılan tüm ülser vakalarında (10 hastada 13 dabetik ayak ülseri) iki haftadan az bir sürede tam debdridman sağlandığını ve bunlardan 11 tanesinin de 7.3 hafta içinde tamamen iyileştiğini belirtmişlerdir ${ }^{17}$. Tüm bu araştırmaları destekler mahiyette 2005 yılındaki bir çalışmamızda 9 günlük LT tedavisinden sonra 11 hastanın 10'unda tam debridman elde edilirken, sadece bir hastada yaranın kısmen temizlendiği gözlenmiştir ${ }^{18}$. Uzun zamandır kronik venöz yetmezliği bulunan 75 yaşındaki bir kadın hastanın ampute edilen ayak parmağının operasyon bölgesinin tekrar enfekte olması nedeniyle tarafımızdan maggot tedavisi uygulanmış; hastanın nekrotik ve süpüratif dokusunun tamamen temizlendiği izlenmiştir. Maggotların uygulanması sırasında hastanın ağrısının artması haricinde önemli bir şikayeti olmamıştır ${ }^{19}$. Ek olarak, son evre böbrek hastalığı, diyabet ve kalp hastalığı dahil çoklu ko-morbiditeleri olan 23 hastanın 17'sinde kompleks diyabetik yaraların LT ile iyileştiği veya tedavi edildiği rapor edilmiştir ${ }^{20}$.

\section{LT ile dezenfeksiyon}

Simmons (1935) steril olmayan L. sericata larvalarının yıkanmasıyla elde edilen sıvıların önemli düzeyde antimik- robiyal özellikler sergilediğini; Pavillard ve Wright (1957) ise larva salgılarının Staphylococcus aureus’a karşı aktif olduğunu göstemişlerdir ${ }^{4,5}$. Thomas ve arkadaşları da (1999), larva çıkartılarının Pseudomonas sp., Streptococcus A ve $B$ ve Staphylococcus aureus'un dirençli suşlarını yok etme veya büyümesini önleme kabiliyeti olduğunu ancak Enterococcus veya Gram negatif bakterilerden Escherichia coli ve Proteus'a karşı herhangi bir etkisinin olmadığını vurgulamışlardır ${ }^{4,5}$.

Günümüzde, larval salgıların MRSA (Metisiline Dirençli Staphylococcus aureus) ve biyofilm üreten bakterilere karşı da etkili olan specin B, defensin A, lucifensinler, alloferon I \& II ve seraticinin gibi antimikrobiyal bileşenleri içerdiği bilinmektedir ${ }^{21-24}$. Bunlardan Lucifensin'in Gram pozitif bakterilere karşı daha fazla antimikrobiyal aktivite gösterdiği vurgulanmıştır ${ }^{25}$.

LT ile dezenfeksiyonu inceleyen birkaç klinik çalışma yapılmıştır. Tantawi ve arkadaşlarının gerçekleştirdikleri çalışmada, haftanın üç günü 13 diyabet hastasına uygulanan LT'nin, yapılan yarı kantitatif değerlendirme ile, ilk LT döngüsünden sonra tüm ülser vakalarında bakteriyel yükü

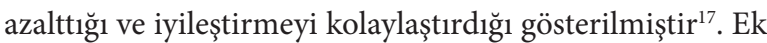
olarak, MRSA ile kolonileşmiş ülseri olan 13 diyabet hastası üzerinde yapılan bir gözlemsel çalışmada, ortalama üç LT uygulamasının MRSA kolonizasyonunu, bir hasta haricinde (\%92), 19 günde elimine ettiği rapor edilmiştir ${ }^{26}$.

Nöroiskemik diyabetik ayak yaraları ve periferik vasküler hastalığı olan 60 yatan hasta üzerinde yapılan başka bir vaka kontrol çalışmasında LT, takip sırasında antibiyotik alınmaması ve daha kısa sürede iyileşme ile ilişkilendirilmiştir ${ }^{27}$. Bunların aksine, başka bir çalışmada ise, MRSA'yı yok etme kapasitesi ve bakteri yükündeki azalma oranlarında LT ve hidrojel grubu arasında anlamlı farklılık tespit edilememiştir ${ }^{13}$.

\section{LT ile büyüme uyarımı}

Larvanın sağlıklı konak hücreleri indükleyip büyüme fak- 
törlerinin salınımına vesile oldukları düşünülmektedir. Yapılan çalışmalarda larvaların hücresel proliferasyonun yanında anjiyogenez, yara yüzeyleri üzerine fibroblast göçünü, vasküler perfüzyonu, ekstrasellüler matriks yeniden şekillendirmeyi, doku oksijenasyonunu ve hatta sinir dokusu büyümesini uyarabildiği gösterilmiştiir ${ }^{4,5,8,28}$.

Kronik 20 ülseri olan 18 hastayı içeren bir kohort çalışmasında LT, nekrotik dokuda azalma, daha hızlı doku büyümesi ve daha yüksek yara iyileşme oranları ile bağlantılı bulunmuştur ${ }^{29}$. Ek olarak, Armstrong ve arkadaşlarının yaptığı çalışmada, LT grubunun kontrol grubuna kıyasla daha çabuk iyileştiği ve amputasyona maruz kalma olas1lıklarının üç kat daha az olduğu rapor edilmiştir27.

$\mathrm{Bu}$ verilerin aksine, yapılan başka bir çalışmada, LT ile debridman süresinin daha kısa olmasına rağmen, iyileşme süresinin hidrojel grubuna kıyasla bir değişikliğe uğramadığı belirtilmiştir ${ }^{13}$. Söz konusu çalışmaya dahil edilen hasta sayısının düşük olmasına ek olarak bu çelişkili veri ayrıca araştırma tasarımındaki farkılılar ile de açıklanabilir; bazı salgıların debridman ile ilişkiliyken bazılarının da büyüme uyarımını indüklediği bilinmektedir. Sherman ve Mumcuoglu, bu çalışma hakkında yazmış oldukları editöre mektupta da bu konu üzerinde durmuşlar ve daha güvenilir bir veri için şu iki ilave adımın eklenmesini önermişlerdir: tekrar bir debridman ya da büyüme uyarım ihtiyacı için hasta/yara takibi ve gerektiğinde LT’nin yeniden uygulanmasi ${ }^{30}$.

Öte yandan, LT’nin ayrıca doku onarımı lehine immün yanıtı manipüle edebildiği öne sürülmüştür. Yapılan bir çalışmada, ham L. sericata tükürük bezi ekstresinin opsonize zimozan ile uyarılan kan süperoksit üretimi ve miyeloperoksidaz salınımını azalttığı gösterilmiştir ${ }^{31}$. İlaveten, larval salgıların pro-enflamatuar sitokin (örneğin, TNF-a, IL-12p40) üretimi üzerinde olumsuz bir etkiye sahipken anti-enflamatuar sitokin IL-10'un ekspresyon seviyelerini arttırdığı tespit edilmiştir. Bununla birlikte, aynı çalışmada larval salgiların, fagositoz ve S. aureus'un insan mo- nositleri tarafından hücre içi öldürülmesini etkilemediği rapor edilmiştir ${ }^{32}$. Buna benzer bir şekilde, aynı grup tarafından yapılan başka bir çalışmada, salgı/sekresyonların (ES), fMLP ile aktive edilmiş nötrofillerin elastaz salınım ve $\mathrm{H} 2 \mathrm{O} 2$ üretimlerini inhibe ettiği, öte yandan Candida albican’nn nötrofiller tarafından fagositoz ve hücre içi öldürülmesini etkilemediği gözlenmiştir ${ }^{33}$. L. sericata ES ürünlerinin ayrıca NF-kB (p65) aktivitesini azaltarak ve kollajen sentezini indükleyerek yara iyileşmesini kolaylaştırdığı öne sürülmüştür ${ }^{34}$. Genel olarak bu veriler larvanın, fagositoz veya apoptozisi etkilemeyerek, yara iyileşmesini bozduğu bilinen proinflamatuar bağışıklık tepkisini azaltıp yara iyileşmesine yardımcı olabileceğini düşündürtmektedir8.

\section{OLGU SUNUMU}

ED, 69 yaşındaki kadın hastada son üç ayda gittikçe genişleyen ve derinleşen bası yarasının LT öncesi ve üç günlük tedaviden sonraki durumu Şekil l'de sunulmuștur.
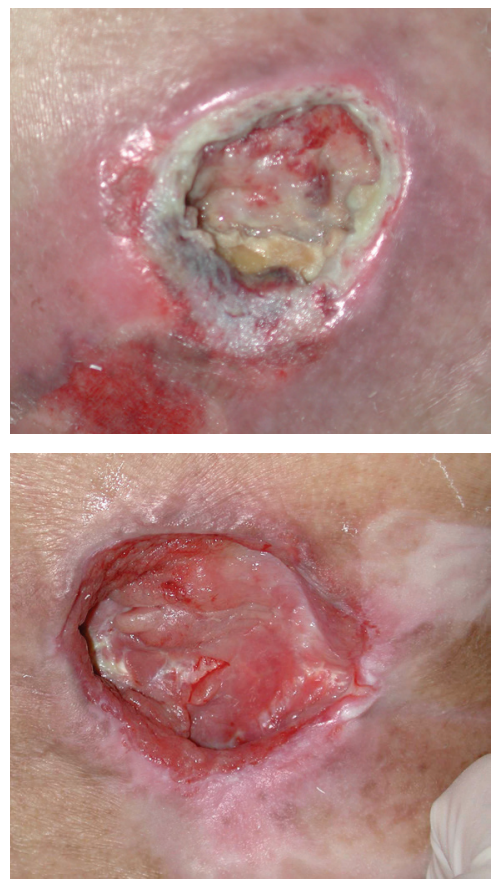

Şekil 1. 69 yaşındaki kadın hastada son üç ayda gittikçe genişleyen ve derinleşen bası yarasının LT öncesi (A) ve üç günlük tedaviden sonraki (B) durumu. 


\section{ÖZEL DURUMLAR VE UYARILAR}

LT’nin en yaygın yan etkisi, larvaların büyümeleri ile artış gösteren ve tedavinin ilk günü içinde gelişen ağrıdır. $\mathrm{Bu}$ durum, analjezik kullanılarak veya ağrı devam ederse sargı ve larvaların çıkarılmasıyla aşılabilir². Cerrahi debridmanı takiben hemen LT kullanılmasına bağlı olarak pıhtılaşmış kanın larvalar tarafından sindirilmesiyle kılcal damarların zarar görmesi sonucu kanama riski olduğu da bildirilmiş̧$\operatorname{tir}^{35}$. Nadiren görülen bu kanama genellikle şiddetli değildir ve antikoagülan ilaçlarla rahatlıkla kontrol edilebilir. Ancak yaranın büyük kan damarlarına yakın olması ve antikoagülasyon kullanımı durumunda risk $\operatorname{artar}^{36}$. Ayrıca LT, aşırı sızıntılı veya hayati iç organlarla bağlantısı olan yaralar için bir tedavi seçeneği olarak önerilmemekte$\operatorname{dir}^{2,4,5}$. LT tabanlı çalışmalarda nadiren ateş, grip benzeri semptomlar ve kaşıntı hissi de bildirilmiştir. LT’nin bir yara tedavisi stratejisi olarak yayılımını kısıtlayabilecek diğer bir faktör de hastaların vücutlarında canlı larva dolaşması fikrinden duydukları psikolojik rahatsızlıktır ${ }^{5}$.

Hastaların larvaları nemli tutmak için ısıtıcıya veya ateşe yakın durmamaları ve larvaları ezmemeye özen göstermeleri önerilmektedir ${ }^{35}$. Zayıf doğaları gereği, teslimat gecikmeleri ve yüksek sıcaklıklar larvaların hayatta kalmalarını olumsuz yönde etkiler. Bu nedenle larvaların gece kurye ile gönderilmeleri ve hastaya uygulanmalarından en az 24 saat önce hastaneye veya kliniklere ulaştırılması tavsiye edilmektedir².

Larvalar yaralardan kaçabilir ve bu nedenle pansumanın larvaları güvenli bir şekilde kapladığından emin olmak gerekmektedir. Ayrıca, yakın zamanda geliştirilen paket yönteminin, larvaları tamamen çevreleyen/içeren ve aynı zamanda sinirler ile larva arasındaki teması sınırlayarak hastanın rahatsızlık riskini azaltıcı bir etkisi vardır. Buna karşılık, "kafes tarzı pansuman" bir yandan larvaların yaraya tam erişimini sağlarken diğer yandan da kaçmalarını önler ${ }^{2,4,5}$.

\section{SONUÇ}

Kronik yaraların tedavisi pahalıdır ve LT sadece ayak ülserleriyle ilişkili olanlar için değil, aynı zamanda çeşitli enfeksiyonlar, çok ilaca dirençli bakteri kolonizasyonu, leishmaniasis ülserleri vb. için de alternatif ve uygun maliyetli bir tedavi stratejisi sunmaktadır. Küresel olarak anti-bakteriyel dirençli bakteri prevalansının artması nedeniyle LT’nin yara tedavisindeki öneminin gelecekte daha da artacağı düşünülmektedir. Amerikan Gıda ve İlaç İdaresi (FDA) LT'yi, nöropatik ve basınç ülser etiyolojisine sahip, venöz staz, travma veya ameliyatın yol açtığ kronik cilt ve yumuşak doku yaralarına karşı kullanabileceğini onaylamıştır. Bununla birlikte, yayınlanan literatürlerin neredeyse tümü LT kullanımını desteklemesine karşın yapılan karşılaştırmalı klinik çalışmaların sayısı henüz istenen seviyeye ulaşmamıştır. Bu nedenle daha büyük çapta randomize çalışmaların (özellikle büyüme uyarımı ve dezefeksiyon konularında) yapılması gerekmektedir. 
Journal of BSHR 2019;3(Özel Say1):55-60

GAZİ, ÖZKAN, MUMCUOĞLU. Larval Terapi ve Kronik Yaralar

Kaynaklar

1. Oksuz E, Malhan S, Sonmez B, Numanoglu Tekin R. Cost of illness among patients with diabetic foot ulcer in Turkey. World J Diabetes [Internet]. 2016;7(18):462. Available from: http://www.wignet.com/1948-9358/full/v7/i18/462.htm

2. Sherman RA. Maggot therapy takes us back to the future of wound care: New and improved maggot therapy for the 21st century. Journal of Diabetes Science and Technology. 2009. p. $336-44$.

3. Naik G, Harding K. Maggot debridement therapy: the current perspectives. Chronic Wound Care Manag Res. 2017;4:121-128.

4. Mumcuoğlu K, Taylan Özkan A. Dünyada Maggot Terapi. In: Multidisipliner Yaklaşıml Biyolojik temelli Doğal Tedaviler- Biyoterapi (Apiterapi, Hirudoterapi, Maggot tedavi ve İhtiyoterapi), Tanyüksel M, Mumcuoğlu K, Ed., Meta Basım Matbaactlk ABC Yayın ve Eğitim Hizmetleri, İzmir, 2015

5. Mumcuoğlu KY, Taylan Özkan A. Süpüratif kronik yaraların maggot debridman tedavisi. Turkiye Parazitol Derg. 2009;33(4):307-15.

6. Whitaker LS, Twine C, Whitaker MJ, Welck M, Brown CS, Shandall A. Larval therapy from antiquity to the present day: Mechanisms of action, clinical applications and future potential. Postgraduate Medical Journal. 2007. p. 409-13.

7. Davydov L. Maggot therapy in wound management in modern era and a review of published literature. Journal of Pharmacy Practice. 2011. p. 89-93.

8. Sherman RA. Mechanisms of maggot-induced wound healing: What do we know, and where do we go from here? Evidence-based Complementary and Alternative Medicine. 2014.

9. Sherman RA, Wyle F, Vulpe M. Maggot therapy for treating pressure ulcers in spinal cord injury patients. J Spinal Cord Med. 1995;18(2):71-4.

10. Stoddard SR, Sherman RA, Mason BE, Pelsang DJ, Sherman RM. Maggot debridement therapy. An alternative treatment for nonhealing ulcers. Journal of the American Podiatric Medical Association. 1995. p. 218-21.

11. Wayman J, Nirojogi V, Walker A, Sowinski A, Walker MA. The cost effectiveness of larval therapy in venous ulcers. J Tissue Viability. 2000;10(3):91-4.

12. Markevich Y, McLeod-Roberts J, Mousley M, Melloy E. Maggot therapy for diabetic neuropathic foot wounds: a randomized study. In: 36th Annual Meeting of the European Association for the Study of Diabetes. 2000.

13. Dumville JC, Worthy G, Bland JM, Cullum N, Dowson C, Iglesias C, et al. Larval therapy for leg ulcers (VenUS II): Randomised controlled trial. BMJ. 2009;338(7702):1047-9.

14. Wang $S y u$, Wang J ning, Lv D cheng, Diao Y peng, Zhang Z. Clinical research on the bio-debridement effect of maggot therapy for treatment of chronically infected lesions. Orthop Surg. 2010;2(3):201-6.

15. Mudge E, Price P, Neal W, Harding KG. A randomized controlled trial of larval therapy for the debridement of leg ulcers: Results of a multicenter, randomized, controlled, open, observer blind, parallel group study. Wound Repair Regen. 2014;22(1):43-51.

16. Gilead L, Mumcuoglu KY, Ingber A. The use of maggot debridement therapy in the treatment of chronic wounds in hospitalised and ambulatory patients. J Wound Care [Internet]. 2012;21(2):78-85. Available from: http://www.magonlinelibrary.com/doi/10.12968/ jowc.2012.21.2.78

17. Tantawi T., Gohar Y., Kotb M., Beshara F., El-Naggar M. Clinical and microbiological efficacy of MDT in the treatment of diabetic foot ulcers. I Wound Care [Internet]. 2007;16(9):379-83. Available from: http://www.magonlinelibrary.com/doi/10.12968/ jowc.2007.16.9.27868

18. Tanyuksel M, Araz E, Dundar K, Uzun G, Gumus T, Alten B, et al. Maggot debridement therapy in the treatment of chronic wounds in a military hospital setup in Turkey. Dermatology. 2005;210(2):115-8.

19. Taylan Özkan A, Mumcuoğlu KY. Kronik venöz ülserli bir olgunun maggot debridman tedavisi ile sağaltımı Türk Hij Den Biyol Derg, 2007; 64(1), 31-34.
20. Marineau ML, Herrington MT, Swenor KM, Eron LJ. Maggot debridement therapy in the treatment of complex diabetic wounds. Hawaii Med J [Internet]. 2011;70(6):121-4. Available from: http://www.ncbi.nlm.nih.gov/pubmed/22162609\%5Cnhttp://www.pubmedcentral.nih.gov/articlerender.fcgi?artid=PMC3233395

21. Ratcliffe NA, Mello CB, Garcia ES, Butt TM, Azambuja P. Insect natural products and processes: New treatments for human disease. Insect Biochemistry and Molecular Biology. 2011. p. 747-69.

22. Harris LG, Bexfield A, Nigam Y, Rohde H, Ratcliffe NA, Mack D. Disruption of Staphylococcus epidermidis biofilms by medicinal maggot Lucilia sericata excretions/secretions. Int J Artif Organs. 2009;32(9):555-64.

23. Cazander G, Van Veen KEB, Bouwman LH, Bernards AT, Jukema GN. The influence of maggot excretions on paol biofilm formation on different biomaterials. Clin Orthop Relat Res. 2009;467(2):536-45.

24. Cazander G, Van De Veerdonk MC, Vandenbroucke-Grauls CMJE, Schreurs MWJ, Jukema GN. Maggot excretions inhibit biofilm formation on biomaterials. Clin Orthop Relat Res. 2010;468(10):2789-96.

25. Andersen AS, Sandvang D, Schnorr KM, Kruse T, Neve S, Joergensen B, et al. A novel approach to the antimicrobial activity of maggot debridement therapy. J Antimicrob Chemother. 2010;65(8):1646-54.

26. Bowling FL, Salgami E V., Boulton AJM. Larval therapy: A novel treatment in eliminating methicillin-Resistant Staphylococcus aureus from diabetic foot ulcers. Diabetes Care. 2007;30(2):370-1.

27. Armstrong DG, Salas P, Short B, Martin BR, Kimbriel HR, Nixon BP, et al. Maggot therapy in "lower-extremity hospice" wound care: fewer amputations and more antibiotic-free days. J Am Podiatr Med Assoc. 2005;95(3):254-7.

28. Nigam Y, Morgan C. Does maggot therapy promote wound healing? the clinical and cellular evidence. Journal of the European Academy of Dermatology and Venereology. 2016. p. $776-82$.

29. Sherman RA. Maggot therapy for treating diabetic foot ulcers unresponsive to conventional therapy. Diabetes Care. 2003;26(2):446-51.

30. Sherman RA, Mumcuoglu KY. Maggot therapy: apparently a good treatment despite poor study and inadequate analysis (letter to editor in response to Dumville et al, BMJ, 2009, 338:b773),. BMJ. 2009;

31. Pečivová J, Mačičková T, Takáč P, Kovácsová M, Cupaníková D, Kozánek M. Effect of the extract from salivary glands of Lucilia sericata on human neutrophils. Neuroendocrinol Lett. 2008;29(5):794-7.

32. Van Der Plas MJA, Baldry M, Van Dissel JT, Jukema GN, Nibbering PH. Maggot secretions suppress pro-inflammatory responses of human monocytes through elevation of cyclic AMP. Diabetologia. 2009;52(9):1962-70

33. van der Plas MJA, van der Does AM, Baldry M, Dogterom-Ballering HCM, van Gulpen C, van Dissel JT, et al. Maggot excretions/secretions inhibit multiple neutrophil pro-inflammatory responses. Microbes Infect. 2007;9(4):507-14.

34. Tombulturk FK, Kasap M, Tuncdemir M, Polat E, Sirekbasan S, Kanli A, et al. Effects of Lucilia sericata on wound healing in streptozotocin-induced diabetic rats and analysis of its secretome at the proteome level. Hum Exp Toxicol. 2018;37(5):508-20.

35. Menon J. Maggot therapy: a literature review of methods and patient experience. Bristish J Nurs. 2012;21(5):38-43.

36. Shih AF, Little AJ, Panse G, Liu J, Yiu G, Yaggi HK, et al. Maggot therapy for calciphylaxis wound debridement complicated by bleeding. JAAD Case Reports. 2018;4(4):396-8. 